\title{
Descriptions of two new species of Eunice Cuvier, 1817 (Polychaeta: Eunicidae) from coastal islands of the State of São Paulo, Brazil*
}

\author{
J.M.M. NOGUEIRA, T.M. STEINER and A.C.Z. AMARAL \\ Departamento de Zoologia, Instituto de Biologia, Universidade Estadual de Campinas, CP 6109, CEP 13083-970, \\ Campinas, SP, Brazil. E-mail: <jmmnogueira@hotmail.com><tatims@obelix.unicamp.br>
}

\begin{abstract}
SUMMARY: Two new species of Eunice from coastal islands of the state of São Paulo are described, both of them living in colonies of the coral Mussismilia hispida. One species was also collected from a sandy beach. Eunice insularis has short palps and antennae in a horseshoe, without articulations; most of the specimens studied are abranchiate, but some have one branchial filament in a few parapodia. Eunice marconii also has palps and antennae without articulations, in a horseshoe, and 1-3 long slender branchial filaments from the anterior to posteriormost chaetigers. These new species are compared with the morphologically closest congeners.
\end{abstract}

Key words: Eunice, Eunicidae, Mussismilia hispida, systematics, state of São Paulo, Brazil.

\section{INTRODUCTION}

Eunice Cuvier, 1817 is caracterised by having 1 central antenna, 1 pair of lateral antennae, 1 pair of slender dorsolateral palps (formerly considered as an additional pair of antennae), and 1 pair of peristomial cirri (Orrhage, 1995). Chaetae include limbate and pectinate chaetae, compound falcigers, subacicular hooks, and in some species compound spinigers and pseudocompound falcigers; the subacicular hooks and falcigers are protected by paired guards (Fauchald, 1992). Branchiae may be present, and some species have been described with both branchiate and abranchiate forms. However, Fauchald (1992) stated that this character, at least in some species, is

\footnotetext{
*Received November 3, 1999. Accepted September 27, 2000.
}

invariable and therefore these different "forms" should be considered as different species.

Fauchald (1992) reviewed the genus and considered more than 200 species as valid. Other species were not included in his revision, or were described later (Miura, 1986, 1987; Orensanz, 1990; CarreraParra and Salazar-Valejo, 1998; Lu and Fauchald, 1998). In Brazil, 26 species of Eunice have been identified up to the present (Hartman, 1948; Nonato, 1981; Nonato and Luna, 1970; Rullier and Amoureux, 1979; Lana, 1981; Morgado and Amaral, 1981), but except for the species of the southeastern and southern areas, most Brazilian polychaetes are poorly known.

Two new species of Eunice are described herein. Both live in colonies of the stony coral Mussismilia hispida (Verrill, 1902) on coastal islands of the state 
of São Paulo. One of the species was also found in a sandy beach.

\section{MATERIAL AND METHODS}

The specimens described in this paper came from collections made for two independent projects carried out on the coast of the state of São Paulo. The first project examined the intertidal macrofaunal polychaetes along the São Sebastião Channel. The other project analysed the fauna present in colonies of the stony coral Mussismilia hispida (Verrill, 1868) on rocky shores of coastal islands (Nogueira, 1995), and particularly the polychaetes in colonies of the same coral in two islands in the same area (Nogueira, 2000).

For the first project, samples of sediment from every kind of intertidal environment along São Sebastião Channel were collected. The macrofaunal polychaetes were fixed in $4 \%$ formalin, transferred to $70 \%$ alcohol, and identified. Collections were made monthly in 1992-1993 and 1995-1998. The particular collection at Engenho d'Água Beach, São Sebastião Island, a sandy beach where Eunice insularis sp. n. was found, was made in September 1992. For the second project, a total of 18 colonies of the massive coral $M$. hispida were collected on the rocky shores of two islands off the coast of São Paulo: Alcatrazes Island $\left(26^{\circ} 06^{\prime} \mathrm{S}, 45^{\circ} 42^{\prime} \mathrm{W}\right)$, on 30 March 1995 and 4 December 1996, and Laje de Santos $\left(24^{\circ} 19^{\prime} \mathrm{S}, 46^{\circ} 11^{\prime} \mathrm{W}\right)$, on 17 March 1996. On both islands the rocky shores have hemispheric colonies of $M$. hispida scattered over the rocks, as well as large colonies of the cnidarians Palythoa and Zoanthus, and some algal tufts. Corals were fixed in $4 \%$ formalin and later decalcified with formalin-formic acid solution. Polychaetes were sorted from the sediment and transferred to $70 \%$ alcohol prior to identification.

Observations and measurements were made using Nomarski interference contrast optics. Drawings were made with a drawing tube. Scanning electron micrographs of the material were made at the Laboratório de Microscopia Eletrônica, Instituto de Biociências, Universidade de São Paulo. Type material is deposited at the Museu de História Natural, Instituto de Biologia, Universidade Estadual de Campinas (UNICAMP; Catalogue series MHNBPO 74 and MHN-BPO 75).

With this methodology, it was not possible to determine whether these species are truly associated with the corals, or if they are merely cryptic species sheltering beneath the corals.

\section{DESCRIPTION OF SPECIES}

\author{
Family EuniCIDAE Berthold, 1827 \\ Genus Eunice Cuvier, 1817 \\ Eunice insularis sp. n.
}

(Figs. 1-2)

Material examined: 194 specimens, 5 from São Sebastião Island, 21 from Laje de Santos, and 168 from Alcatrazes Island. Holotype: MHN-BPO 74/0, from Alcatrazes, paratypes from São Sebastião: MHN-BPO 74/1-2, paratypes from Laje de Santos: MHN-BPO 74/3-7; paratypes from Alcatrazes: MHN-BPO 74/8-13.

Etymology: The species was named Eunice insularis because, although the area has been extensively studied by Dr. Amaral and associates, it has never been recorded from the mainland of the state of São Paulo, but only from islands.

Description: Holotype complete specimen, with 127 chaetigers, in good condition, about $29.8 \mathrm{~mm}$ long and $1.9 \mathrm{~mm}$ wide, at the level of chaetiger 18 . Body slender, anterior part ventrally flattened, cylindrical from midbody. Prostomium slightly longer than peristomium, superior lip projections distally rounded, inflated dorsally and ventrally, with median sulcus (Fig. 1A, H, I). Palps and antennae in horseshoe, ceratophores short, ring-shaped, without articulations; ceratostyles digitiform, slightly thicker distally, wrinkled, but without true articulations. Palps and lateral antennae very close to each other, separated from central antenna by a gap. Palps reaching posterior border of anterior peristomial ring, lateral antennae reaching midlength of chaetiger 1 , and central antenna reaching midlength of chaetiger 2 . One pair of black eyes, posterior to bases of palps (Fig. 1A). Anterior peristomial ring extending through $3 / 4$ of total peristomium length; separation between peristomial rings distinct on all sides; inferior lip distinct, muscular. Peristomial cirri digitiform, anterior half of anterior peristomial ring. Mandibles with light narrow shafts, and concentric lines on cutting edges (Fig. 2G). Maxillary formula: I- 1+1, II- 6+7, III- 8+0, IV- 8+11, V- 1+1 (Fig. 2H). Branchiae observed in few specimens (absent in holotype), as a single filament, flattened, in few parapodia (Fig. 1D). Dorsal cirri short, tapering, with slightly inflated oval bases; anterior dorsal cirri short (Fig. 1C), becoming even shorter on midbody (Fig. 1E, G), and somewhat longer on posterior ones (Fig. 1F). 

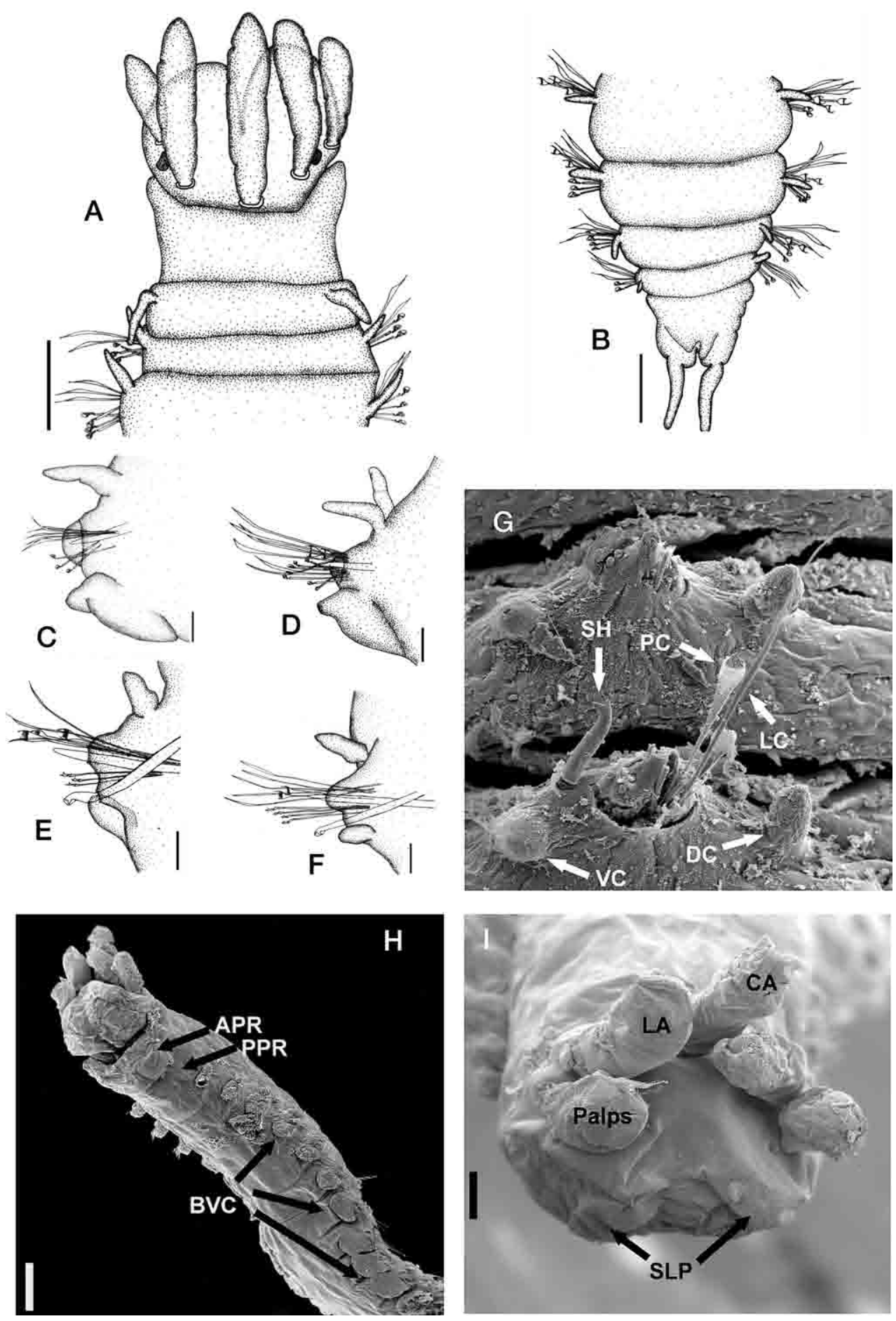

FIG. 1. - Eunice insularis sp. n. A, anterior end, dorsal view; B, pygidium, dorsal view; C, G: parapodia: C, chaetiger 15; D, chaetiger 15 (individual from São Sebastião Island), E, chaetiger 52, F, chaetiger 132, G, chaetiger 63; H, anterior end, lateral view; I, anterior end, frontal view. APR, anterior peristomial ring; BVC, bases of ventral cirri; CA, central antenna; DC, dorsal cirrus; LA, lateral antennae; LC, limbate chaetae; PPR, posterior peristomial ring; PC, pectinate chaetae; SH, subacicular hook; SLP, superior lip projections; VC, ventral cirrus. Scale bars: A, B: $200 \mu \mathrm{m}$; C, F: $100 \mu \mathrm{m}$; G: $47 \mu \mathrm{m}$; H: $500 \mu \mathrm{m}$; I:160 $\mu \mathrm{m}$.

Ventral cirri of first three chaetigers digitiform, without inflated bases; from chaetigers 4-31, with inflated oval bases, and tips short and rounded (Fig. $1 \mathrm{C}, \mathrm{H})$; from chaetigers $32-38$, inflated bases decreasing in size, disappearing from chaetiger 39 on, tips slightly increasing in length and thickness (Fig. 1E, F, G). Limbate chaetae much longer than other chaetae, limb with very short teeth (visible in SEM micrographs; Figs. 1G; 2A, F). Four to six pectinate chaetae per parapodium, symmetrical, 


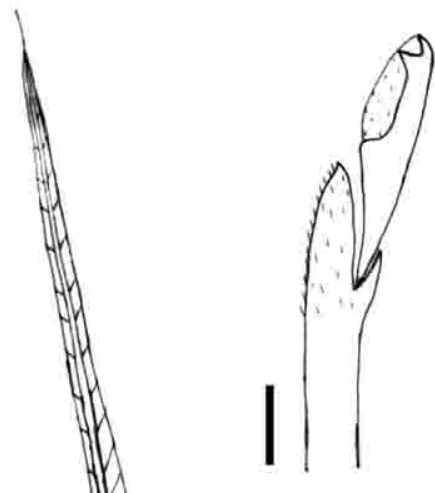

B

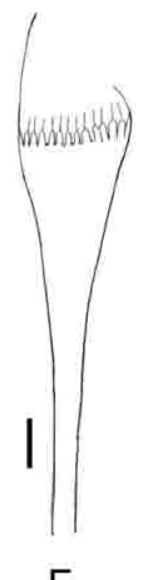

E

A

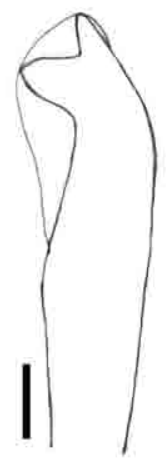

C

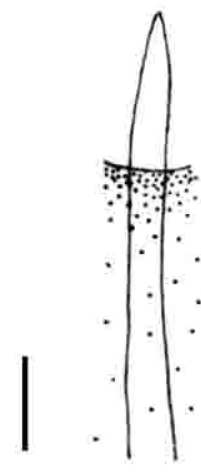

D

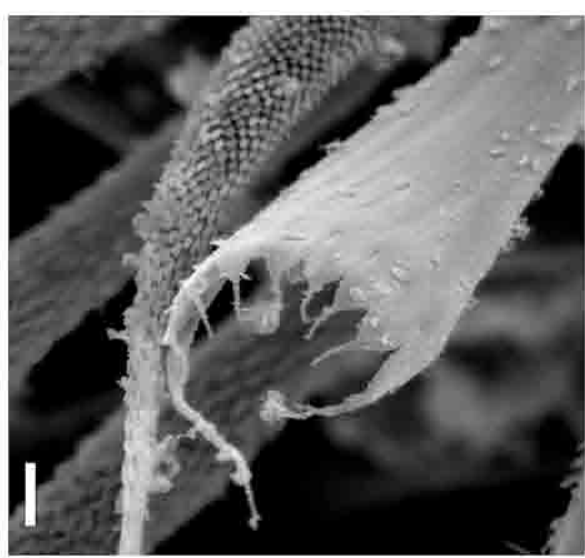

$\mathrm{F}$

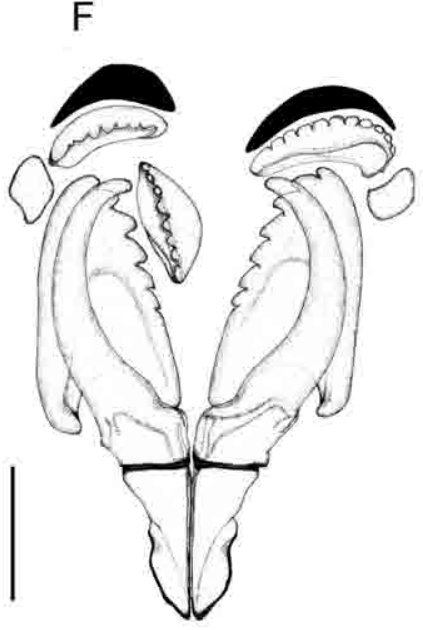

$\mathrm{H}$

FIG. 2. - Eunice insularis sp. n. A, limbate chaeta; B, compound falciger; C, subacicular hook; D, aciculum; E, pectinate chaeta; F, pectinate and limbate chaetae, anterior parapodium; G, mandibles; H, maxillae. Scale bars: A: $50 \mu \mathrm{m} ; \mathrm{B}, \mathrm{C}, \mathrm{E}: 10 \mu \mathrm{m} ; \mathrm{D}: 20 \mu \mathrm{m} ; \mathrm{F}: 4 \mu \mathrm{m} ; \mathrm{G}, \mathrm{H}: 200$

furled, with 10-13 sharp teeth, lateral teeth longer than other teeth, one of the lateral twice as long as the other; other teeth short and stout, abruptly tapering, with filamentous tips (Figs. 1G; 2E, F). Compound chaetae exclusively falcigers, more than 10 on anterior chaetigers, 3-5 from midbody; all chaetae about same length, shafts distally inflated, with minute serrations and short beak. Blades of falcigers strongly bidentate, both teeth directed laterally, separated by wide gap; distal tooth narrower and shorter; guards rounded, covering the blade, denticulated, without mucros (Fig. 2B). One or two acicula per parapodium, straight, bluntly conical, clear and translucent on anterior chaetigers, darkening 
from chaetiger 25-30 (25 in holotype), then dark brown (Fig. 2D). Subacicular hooks from chaetiger 20-28 (27 in holotype), single, brown, bidentate; proximal tooth directed laterally, much larger than upwardly directed distal tooth (Figs. 1G; 2C). Pygidium with 1 pair of anal cirri (Fig. 1B).

Variation: Branchiae were present in one specimen from São Sebastião Island, in some parapodia from chaetigers 15-22, and in several specimens from Alcatrazes Island, on the posterior chaetigers. In addition to the position, the size of the filaments also varied, from very short filaments in the specimen from São Sebastião Island, to spiral filaments, much longer than the dorsal cirri, in some specimens from Alcatrazes. The presence or absence of branchiae does not depend on the size of the worm.

Younger specimens lack peristomial cirri, but are identical to the larger specimens in all other features. The absence of peristomial cirri and branchiae would place those specimens in a different genus, Paramarphysa Ehlers, 1887, but they are in fact merely juveniles of the same species and, as in the case of Eunice wui Lu and Fauchald, 1998, the presence of peristomial cirri depends on the size of the worms.

Discussion: Although Fauchald (1992) considered the presence or absence of branchiae to be a very important character for the identification of a species (at least for some species, such as Eunice cariboea), this is a highly variable character in Eunice insularis. In this species, the branchiate and abranchiate forms are absolutely identical in all other features, and the branchiae, when present, also differ in position and length from one specimen to another. Among branchiate Eunice, the species most similar to E. insularis are E. excariboea Fauchald, 1992 and E. gagzoi Augener, 1922, two species that were frequently identified as branchiate forms of $E$. cariboea Grube, 1856, before Fauchald's review of the genus (1992). Eunice excariboea differs from $E$. insularis in having: palps and antennae with articulated ceratostyles, as well as dorsal cirri; branchiae palmate, with 2-3 filaments instead of 1, as in $E$. insularis; subacicular hooks beginning far posteriorly, from segment 78 in the paratype and segment 87 in the holotype, while in E. insularis they begin from setiger 20-28; and subacicular hooks with proximal tooth shorter than that of E. insularis (Fauchald, 1992). Eunice gagzoi differs from $E$. insularis in that its branchial filaments are longer, as long as the body width where best developed; the pectinate chaetae have both lateral teeth about the same size, and in E. insularis one of the lateral teeth is about twice as long as the other; the blades of the compound chaetae have both teeth directed obliquely distally, while in E. insularis both teeth are directed laterally; the acicula have bent tips, versus the straightly tapering, distally blunt condition, as in $E$. insularis; subacicular hooks with proximal tooth much larger, strongly bent, pointed, basally directed, while in E. insularis the corresponding tooth is straight, distally blunt, laterally directed; and the maxillary formula is different from E. insularis (Fauchald, 1992).

On the other hand, among abranchiate species there is a group with small palps and antennae in a horseshoe, without articulations, where E. insularis fits quite well. This group includes 5 species besides E. insularis: E. cariboea, E. cincta (Kinberg, 1865), E. goodei Fauchald, 1992, E. imogena (Monro, 1924), and E. wasinensis Fauchald, 1992. Table 1 lists the features of the 6 species.

Eunice cincta seems to be morphologically closest to E. insularis, but its description is incomplete and, according to Fauchald (1992), the holotype is damaged, making more precise analysis impossible. We rely on the differences in the size of palps, antennae, and peristomial cirri, as well as in the shape of the tips of the ventral cirri, in considering it as a different species. Moreover, E. cincta is known from the Society Islands in the Pacific Ocean, and has never been found in the Atlantic.

Habitat: Eunice insularis was found associated with a stony coral, and in a sandy beach with coarse sand and stones of different sizes, being much more common and abundant in the corals.

\section{Eunice marconii sp. n.}

(Figs. 3-4)

Material examined: 41 specimens, all from Alcatrazes Island. Holotype: MHN-BPO 75/0, paratypes: MHM-BPO 75/1-10.

Etymology: The name Eunice marconii is given in homage to Marconi Holanda Mendes, who has extensively assisted the senior author and made it possible for him to conclude his $\mathrm{Ph}$. D. course.

Description: Holotype complete specimen, with 287 chaetigers and $133 \mathrm{~mm}$ in length. Body robust, flattened ventrally, on anterior chaetigers, cylindrical from midbody. Prostomium shorter, slightly narrow- 


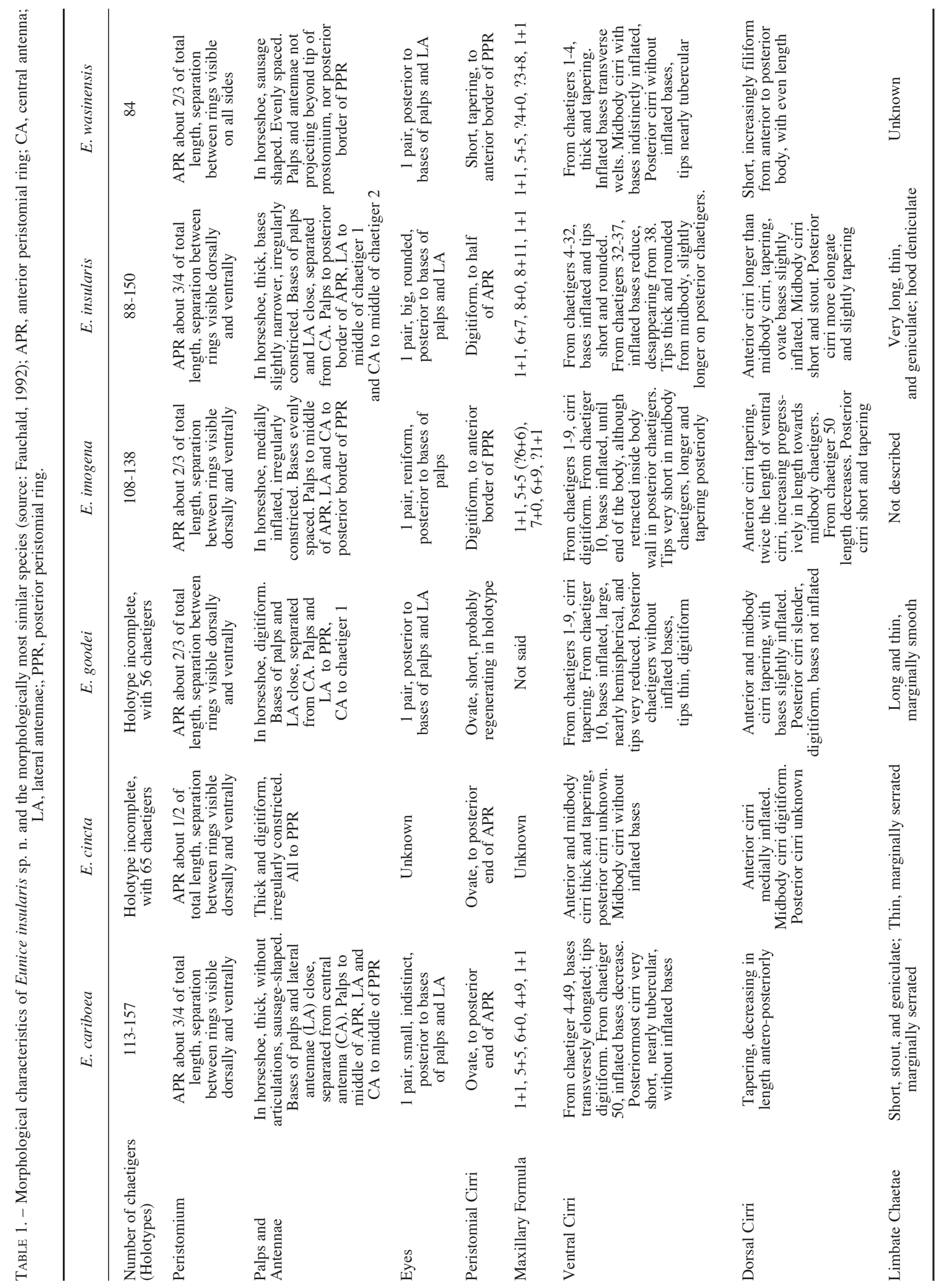




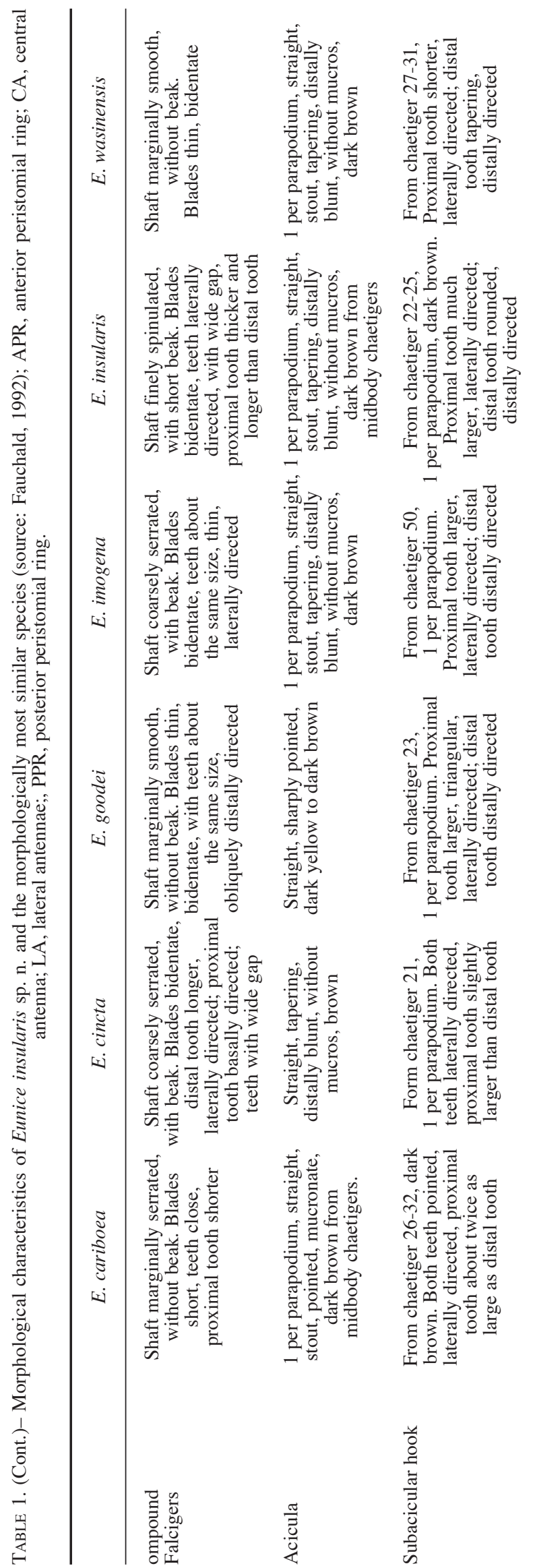

er, and less than half as deep as peristomium (Fig. 3A, G, H). Upper lip projections rounded, dorsally and ventrally inflated, median sulcus deep (Fig. 3G, H); inferior lip distinct, muscular (Fig. 3A, G). Anterior peristomial ring about $5 / 6$ of total peristomium length, separation between rings distinct dorsally and ventrally. Palps and antennae in horseshoe, bases covered by a fold of peristomium, palps and lateral antennae close, central antenna separated by a gap; ceratophores ring-shaped, without articulations; ceratostyles distally rounded in adults (Fig. 3A, G, H), tapering in juveniles. Palps reaching midlength of anterior peristomial ring, lateral antennae reaching midlength of posterior peristomial ring, central antenna reaching chaetiger 1 . Peristomial cirri subulate, reaching anterior half of anterior peristomial ring (Fig. 3A, G). Mandibles with light shafts and many concentric lines in the cutting edges, without distal expansions (Fig. 4G). Maxillary formula: I1+1, II- 6+4, III- 6+0, IV- 2+8, V- 1+1, VI- elongate plates; Mx II with 2 dark chitinous plates, superior and inferior (Fig. 4H; present near both Mx II, drawn only in one); Mx V with superior tooth, evident in lateral view (Fig. 4H). Dorsal cirri long and filiform, with 2-4 very thin acicula; palmate branchiae present from chaetiger 21-23 to posteriormost chaetigers, 1 single filament on anterior chaetigers, then 2 , and occasionally 3 filaments (Fig. 3D-F). Inflated bases of ventral cirri present from chaetiger 4, initially ovate, as stout ventral ridges with short tips from chaetigers 7-44; bases reduced from chaetiger 45 and disappearing from chaetiger 50 (visible with light microscope), tips slightly longer; posterior ventral cirri with bases ovate and tips more elongate (Fig. $3 C-G)$. Three to five limbate chaetae per parapodium, thin, limb minutely denticulate (seen with SEM), slightly longer than other chaetae, especially on anterior chaetigers (Fig. 4A). Five to eight pectinate chaetae, slightly asymmetrical, very slender, furled, with 10-13 sharp teeth, one of the lateral teeth longer (Fig. 4E, F). Compound chaetae exclusively falcigers, shafts slightly inflated distally, short spinulation, beak indistinct; many chaetae in anterior and posterior chaetigers, 5-8 in midbody. Blades of falcigers strongly bidentate, teeth laterally directed; in anterior chaetigers, with teeth about the same size; from midbody, proximal tooth larger; blade guards rounded, covering the blade, denticulate, without mucros (Fig. 4B). Acicula expanded distally and laterally into hammer-head structure, 2 in anterior chaetigers, 1 from midbody; younger specimens with additional aciculum in posterior chaetigers, straight, 

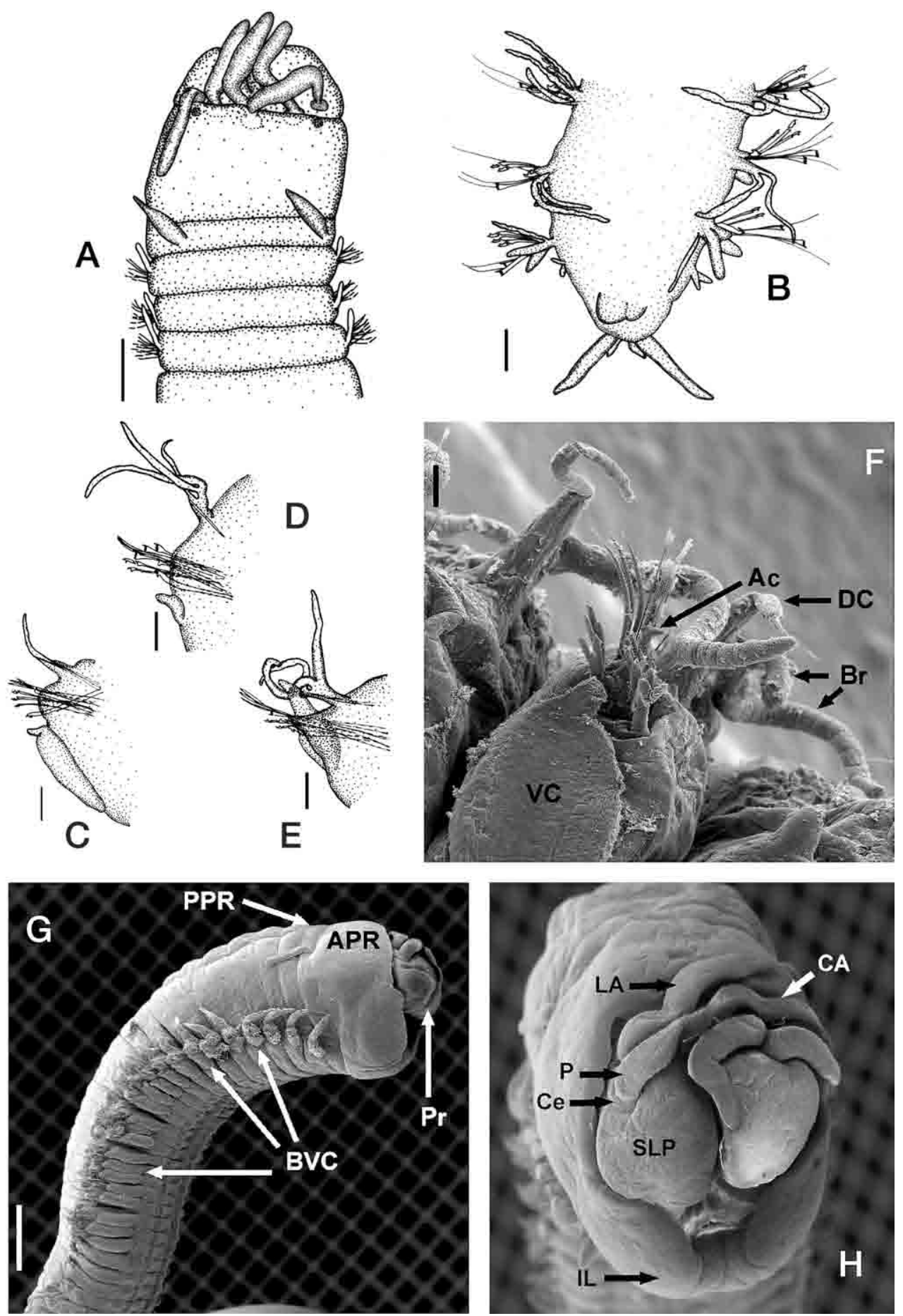

FIG. 3. - Eunice marconii sp. n. A, anterior end, dorsal view; B, pygidium; C, E, parapodia: C, chaetiger 10, D, chaetiger 65 , E, chaetiger 274; F, chaetiger 47, G, anterior end, lateral view, H, anterior end, frontal view. Ac, aciculum; APR, anterior peristomial ring; Br, branchiae; BVC, bases of ventral cirri; CA, central antenna; Ce, ceratophore; DC, dorsal cirrus; IL, inferior lip; LA, lateral antenna; P, palps; PPR, posterior peristomial ring; Pr, prostomium; SLP, superior lip projections; VC, ventral cirrus. Scale bars: A, B: $1000 \mu \mathrm{m} ; \mathrm{C}, \mathrm{E}: 300 \mu \mathrm{m}$; F: $150 \mu \mathrm{m}$; G: $120 \mu \mathrm{m}$; H: $50 \mu \mathrm{m}$.

tapering, mucronate (Fig. 3F, 4D). Single subacicular hook per parapodium from chaetiger 17-25 to the end of the body, 2 in some posterior chaetigers; hook with rounded hood, bidentate, proximal tooth much larger, basally directed, distal tooth laterally directed
(Fig. 4C); tridentate hook only seen in 2 posterior chaetigers on holotype, with teeth in a crest: proximal tooth larger, basally directed, intermediate tapering, about same size as distal tooth, laterally directed, and distal tooth upwardly directed. Pygidium 

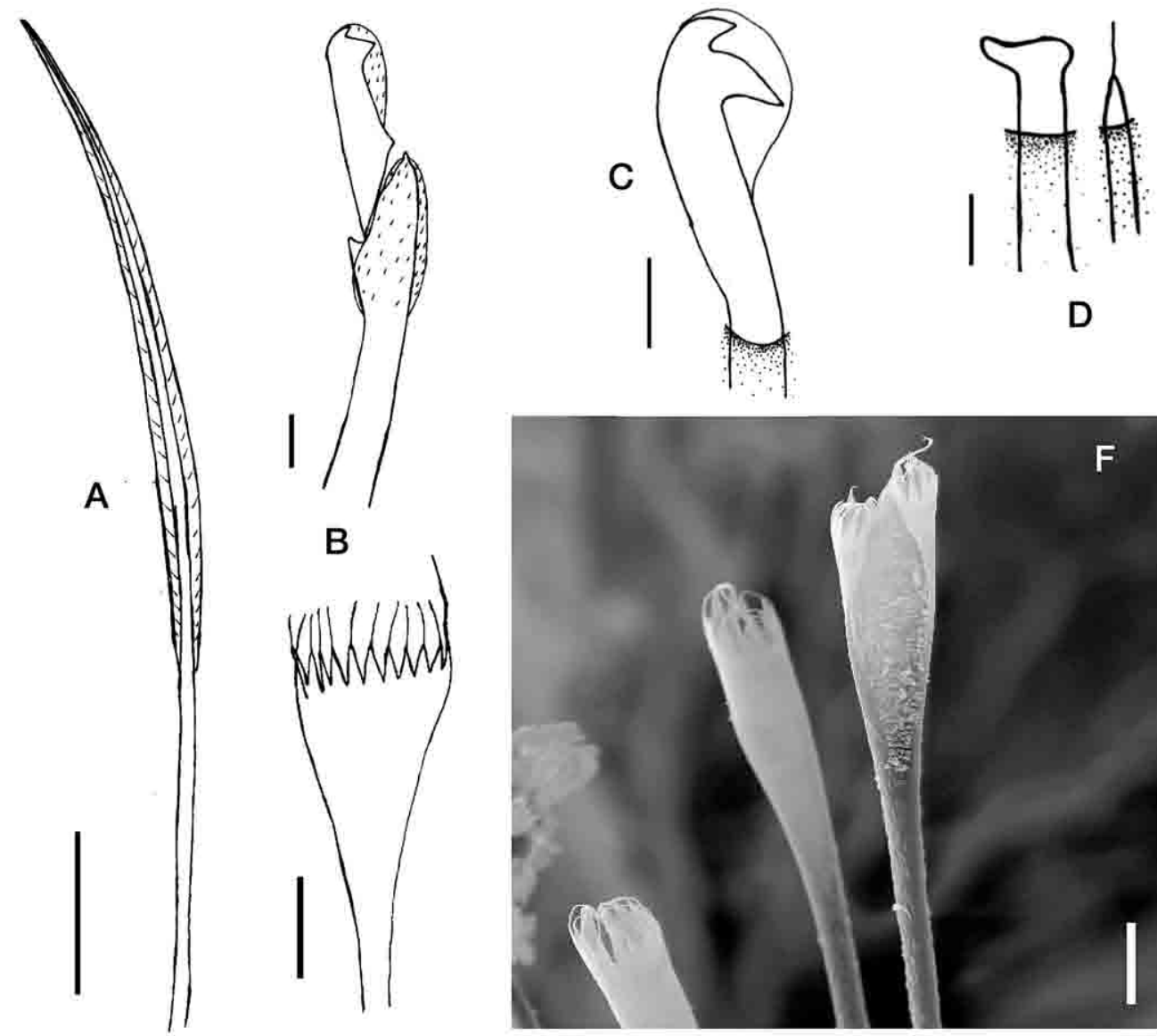

D

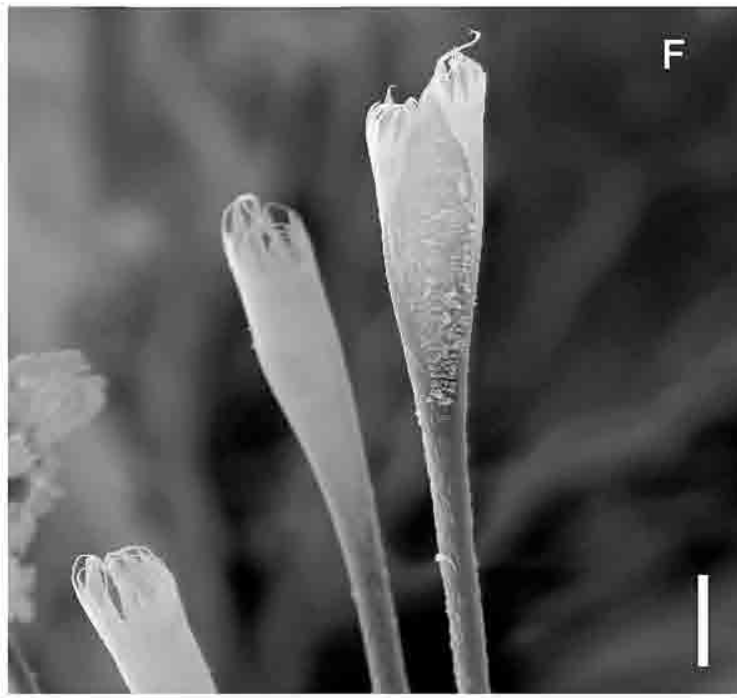

E

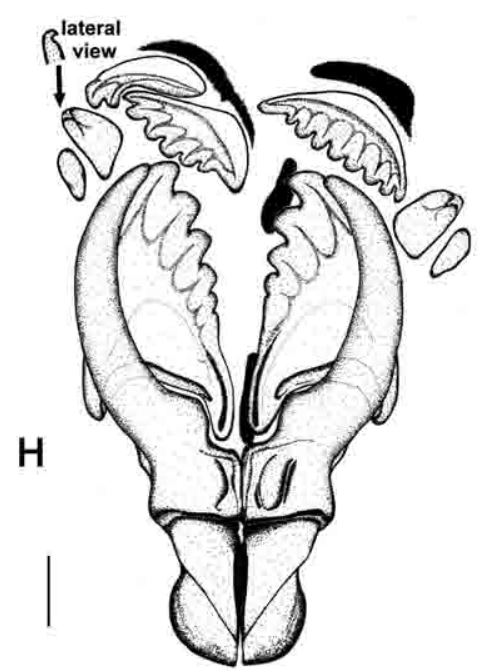

FIG. 4. - Eunice marconii sp. n. A, limbate chaeta; B, compound falciger; C, subacicular hook; D, acicula; E-F pectinate chaetae; G,

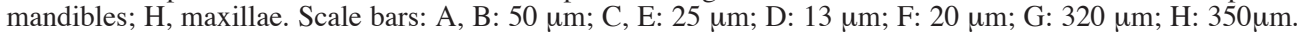

with 2 pairs of anal cirri, superior pair about four times as long as inferior pair (Fig. 3B).

Discussion: Eunice marconii is similar to E. filamentosa Grube, 1856 and E. spongicola (Treadwell, 1921), two very close species, which have long been considered synonymous (Hartman, 1956; Fauchald,
1992). Eunice marconii is somewhat intermediate between them, apparently closer to E. filamentosa, as can be seen in Table 2. However, the differences, mainly in the jaws, branchiae, and acicula, are sufficient to consider it a separate species.

The most distinctive character of E. marconii is the structure of the jaws. Eunice spongicola was 
TABLE 2. - Morphological characteristics of Eunice marconi and the morphologically most similar species (sources: Treadwell, 1921; Fauchald, 1992); APR, anterior peristomial ring; CA, central antenna; LA, lateral antennae; PPR, posterior peristomial ring.

\begin{tabular}{lc}
\hline & Eunice filamentosa \\
\hline $\begin{array}{l}\text { Number of chaetigers } \\
\text { (Holotypes) }\end{array}$ & 119 \\
Prostomium & $\begin{array}{c}\text { Shorter and narrower than peris- } \\
\text { tomium, and less than half as deep; } \\
\text { upper lip projections frontally } \\
\text { truncated, dorsoventrally flattened, } \\
\text { median sulcus deep }\end{array}$
\end{tabular}

Peristomium

Palps and antennae

Palps and LA close, with gap to CA. Palps to middle of anterior peristomial

Mandibles

Maxillary formula

Peristomial cirri

Branchiae

From chaetigers 23-27 to posteriormost

Ventral cirri

Capillary chaetae Pectinate chaetae

Compound

falcigers

Acicula

Subacicular hook From chaetiger 17-22. 1 per parapodium; proximal tooth much larger, basally directed; distal tooth distally blunt, laterally directed; hood truncated

Eunice marconii

Eunice spongicola

287

152

Tapering anteriorly. APR about 7/8 of total length; separation between rings visible dorsally and ventrally ring; LA and CA to chaetiger 1

With distal expansion on cutting edges

$$
1+1,4+4,6+0,4+9,1+1
$$

Slender, digitiform, to middle of anterior peristomial ring chaetigers, longer than dorsal cirri.

1 flattened filament, short, on

anterior and midbody chaetigers;

2 filaments much longer, nearly as long as body width, on posterior chaetigers

Shorter and slightly narrower than peristomium, and less than half as deep; upper lip projections rounded, dorsoventrally inflated, median sulcus deep

APR about $5 / 6$ of total length; separation between rings visible dorsally and ventrally

Bases of palps and antennae covered by peristomial fold; palps and LA close, with gap CA. Palps to middle of anterior peristomial ring; LA to posterior border of anterior peristomial ring; $\mathrm{CA}$ to chaetiger 1

Without distal expansion on cutting edges

$$
\begin{aligned}
& 1+1,6+4,6+0,2+8,1+1, \mathrm{Mx} \text { VI } \\
& \text { as elongate plates }
\end{aligned}
$$

Tapering, to half of anterior peristomial ring

From chaetigers $23-27$ to posteriormost chaetigers; longer than dorsal cirri; 2 filaments in most chaetigers

Bases inflated from chaetiger 4, as thick ventral ridge from 15-50, short tips; posterior cirri digitiform, bases not inflated

Slender, marginally smooth Shafts stout, blades furled; about 12 teeth

Shafts serrated, beak distinct. Blades bidentate, proximal tooth much longer, basally directed; distal tooth tapering, obliquely distally directed

2 per parapodium, symmetrical hammer-head shaped

Shafts with spinulation short, beak

\section{Inf}

Inflated bases ovate, from chaetigers 4-6, as stout ventral ridges from chaetigers 7-45; tips very small. From chaetiger 50, cirri slightly longer, bases not inflated

Slender, hood denticulate 5-8 per parapodium, furled, about 10-13 sharp teeth indistinct. Blades bidentate, both teeth laterally directed; from midbody, proximal tooth larger

2 per parapodium, 1 from midbody, asymmetrical hammer-head shaped. Younger specimens with additional acicula posteriorly, straight and mucronate

From chaetiger $17-25,1$ per parapodium, 1-2 in posterior chaetigers; proximal tooth much larger, basally directed; distal tooth laterally directed, distally blunt; hood rounded. Tridentate hooks may be present in few posterior chaetigers
Shorter and narrower than peristomium, and less than half as deep; upper lip projections frontally truncated, dorsoventrally flattened, median sulcus deep

About twice as large and as broad as prostomium. APR about $5 / 6$ of total length; separation between rings only seen ventrally

Evenly spaced. All ending before posterior border of peristomium
Without distal expansion on cutting edges

$$
1+1,4+4,7+0,3+5,1+1
$$

Digitiform, to posterior end of anterior peristomial ring

From chaetiger 24 to last, not present on posteriormost; longer than dorsal cirri; most chaetigers with 3 filaments

From chaetiger 4-50 inflated bases ovate; narrow digitiform tips.

Posterior cirri digitiform

Long and slender, marginally serrated Flat, about 15 teeth

Shafts serrated, beak indistinct; blades bidentate, teeth about the same size, distal laterally directed, proximal slightly more basally

1 per parapodium, asymmetrical hammer-head shaped

From chaetiger 26; 1 per parapodium; bidentate; proximal tooth much larger, basally directed; distal tooth digitiform, distally blunt 
described by Treadwell (1921) and redescribed by Fauchald (1992) and, although these authors did not agree about the number of teeth in some plates, neither of them mentioned either the presence of Maxilla VI or the chitinous plates observed superiorly and inferiorly on Maxilla II, as in E. marconii. The same occurs in Treadwell's description of E. filamentosa (1921).

Habitat: Eunice marconii was found inside thick mucous tubes in algal tufts or other biogenic structures in dead areas of the coral colonies.

\section{ACKNOWLEDGEMENTS}

We would like to thank $\mathrm{CNPq}$, the Conselho Nacional de Desenvolvimento Científico e Tecnológico and FAPESP, Fundação de Amparo à Pesquisa do Estado de São Paulo, for financial support for this study; the professors of the Postgraduate Course of IB-USP, especially Dr. Erika Schlenz and Dr. Fábio Lang da Silveira; the staff of the Laboratório de Microscopia Eletrônica do IB-USP, partially supported by Auxílio PROAP/98-CAPES, especially Technician Ênio Mattos; Dr. Fausto Pires de Campos and Dr. Tatiana Neves of the Instituto Florestal (IF) for allowing us to collect on both islands, which are protected areas; Dr. Carlos E. F. da Rocha (IB-USP), for lending us his drawing tube; and Dr. Janet W. Reid for revising the English text.

\section{REFERENCES}

Carrera-Parra, L.F. and S.I. Salazar-Valejo. - 1998. A new genus and 12 new species of Eunicidae (Polychaeta) from the
Caribbean Sea. J. Mar. Biol. Ass. U. K., 78: 145-182.

Duarte, L.F.L. and R.C. Nalesso. - 1996. The sponge Zygomicale parishii (Bowerbank) and its endobiotic fauna. Estuar. Coast. Shelf Sci., 42: 139-151.

Hartman, O. - 1948. The marine annelids erected by Kinberg, with some notes on some other types in the Swedish State Museum. Ark. Zool. Stockholm, 42(1): 1-137.

Hartman, O. - 1956. Polychaetous annelids erected by Treadwell, 1891 to 1948 , together with a brief chronology. Bull. Am. Mus. Nat. Hist., 109 (2): 239-310.

Fauchald, K. - 1992. A review of the genus Eunice based upon type material. Smithson. Contrib. Zool., 523: 1-421.

Lana, P.C. - 1981. Padrões de distribuição e diversidade específica de anelídeos poliquetos na região de Ubatuba, estado de São Paulo. M.Sc. dissertation, Universidade de São Paulo. 111 pp.

Lu, H. and K. Fauchald. - 1998. Description of Eunice weintraubi and $E$. wui, two new species of eunicid polychaetes from northern Gulf of Mexico. Proc. Biol. Soc. Wash., 111 (1): 230-240.

Miura, T. - 1986. Japanese polychaetes of the genera Eunice and Euniphysa: Taxonomy and branchial distribution patterns. Publ. Seto Mar. Biol. Lab., 31 (3/6): 269-325.

Miura, T. -1987 . New or little known species of the family Eunicidae (Annelida Polychaeta) from Japan. Proc. J. Soc. Syst. Zool., 36: $1-9$.

Morgado, E.H. and A.C.Z. Amaral. - 1981. Anelídeos poliquetos associados a um briozoário. I. Eunicidae, Lumbrineridae, Lysaretidae e Dorvilleidae. Iheringia (Sér. Zool.), 60: 33-54.

Nalesso, R.C., L.F.L. Duarte and I. Pierozzi, Jr. - 1995. Tube epifauna of the polychaete Phyllochaetopterus socialis Claparède. Estuar. Coast. Shelf Sci., 41: 91-100.

Nonato, E.F. - 1981. Contribuição ao conhecimento dos anelídeos poliquetas bentônicos da plataforma continental brasileira , entre Cabo Frio e o Arroio Chuí. Tese de Livre Docência, Universidade de São Paulo. 246 pp.

Nonato, E.F. and J.A.C. Luna. - 1970. Anelídeos poliquetas do Nordeste do Brasil. I. Poliquetas bentônicas da costa de Alagoas e Sergipe. Bolm. Inst. Oceanogr., S. Paulo, 19: 57-130.

Orensanz, J.M. - 1990. The eunicemorph polychaetes from Antarctic and Subantarctic seas. In: Kornicker, L. S. (ed.): Biology of the Antarctic Seas XXI. Antarctic Res. Ser., 52: 1-183.

Orrhage, L. - 1995. On the innervation and homologues of the anterior end appendages of the Eunicea (Polychaeta), with a tentative outline of a fundamental constitution of the cephalic nervous system of polychaetes. Acta Zool. Stockholm, 72: 233-246.

Rullier, F. and L. Amoureux. - 1979. Annélides polychètes. Campagne de la Calypso au large des côtes atlantiques de l'Amérique du Sud (1961-1962). Ann. Inst. Océanogr., 55: 10-206.

Treadwell, A.L. - 1921. Leodicidae from the West Indian Region. Publ. Carn. Inst. Washington 15 (293): 1-131.

Scient. ed.: J.M. Gili 